\section{Fatores Culturais Associados à Doença da Reclusão do Alto Xingu (Brasil Central)*}

\author{
(Considerações antropológicas sobre a abordagem \\ epidemiológica)
}

Sob uma abordagem antropológica da dimensão simbólica da doença, o artigo enfoca as representaçôes sobre a sindrome característica do ritual da reclusão pubertária entre indigenas da região do Alto Xingu (Brasil Central), em uma perspectiva comparativa com a abordagem clínico-epidemiológica clássica. A categoria tradicional da medicina indigena é considerada como ponto de partida para o contraste com a categoria da medicina ocidental, identificada em alguns casos da sindrome como uma neuropatia periférica de origem possivelmente tóxica. O tratamento epidemiológico dos dados sobre a categoria tradicional evidencia relações com acontecimentos de ordem cultural, afetos à conjuntura sócio-política e das relações de contato. Essa "síndrome cultural" representa um desafio aos métodos utilizados pela medicina ocidental moderna, em particular para a abordagem clínica e epidemiológica. Finalmente, os autores apresentam consideração de ordem metodológica, explicitando aspectos de dimensão cultural, especificos da sociedade moderna, contidos nos procedimentos das disciplinas cientificas envolvidas.

\title{
INTRODUÇÃO
}

O objetivo deste artigo é apresentar algumas contribuições que a antropologia social pode dar à epidemiologia, enfocando a questão das determinações culturais do

* Este artigo baseia-se em dados da pesquisa para a dissertação de mestrado da autora, defendida em 1991 no Programa de Pós-graduação em Antropologia Social do Museu Nacional.

** Núcleo de Estudos em Saúde de Populações Indigenas, Escola Nacional de Saúde Pública (Ensp/Fiocruz), Avenida Brasil, 4036, sala 707, Rio de Janeiro, RJ, 21040, Brasil.

** Departamento de Epidemiologia e Métodos Quantitativos em Saúde da Ensp/Fiocruz 
processo saúde-doença, a partir do exame de fatores associados a uma doença de uma sociedade culturalmente diferenciada. Permeia questões como a da interdisciplinaridade e a da complementaridade entre os métodos quantitativo e qualitativo, a partir da percepção de que cada ordem de fatores é determinante do processo saúde-doença em niveis distintos.

O papel dos determinantes culturais (cultura é entendida aqui no seu sentido de sistema simbólico) do processo saúde-doença pode ser examinado em dois níveis. $O$ primeiro é aquele em que os fatores culturais revestem-se, sobretudo, de uma apresentação empírica, podendo-se identificar percepções distintas das doenças e padrões de comportamento na clientela que interferem no comportamento das doenças ou têm implicações de natureza etiológica. O segundo nível refere-se às representações $\mathrm{e}$ categorias cognitivas dos agentes sociais do conhecimento. Enquanto produção científica, todavia, as categorias da medicina ocidental não estão isentas de uma implicação cultural na sociedade ocidental moderna, podendo ser permeadas por ideologias diversas.

Estes dois níveis de apreensão dos fatores culturais, que estão presentes em qualquer sociedade, poderiam ser examinados nas sociedades ditas complexas. $O$ deslocamento dessa preocupação para uma sociedade "simples", onde o universo total reduz-se a cerca de 1500 habitantes, e em que a constatação da diversidade cultural é predominante para os agentes do conhecimento científico, pode contribuir para explicitar melhor o papel destes fatores.

\section{A DOENÇA DA RECLUSĀO: UMA QUESTÃO DE PONTO DE VISTA CONCEITUAL}

Durante o ano de 1979, alguns óbitos ocorridos na área indígena do Alto Xingu (Mato Grosso) despertaram o interesse dos profissionais de saúde da área e de pesquisadores em medicina clínica e epidemiologia, devido tanto à letalidade quanto à intrigante dificuldade de classificação nosológica e etiológica de uma síndrome aguda conseqüente à reclusão pubertária, um rito de passagem (cf. Van Gennep, 1978) daquela cultura.

Doença da reclusão foi o termo utilizado inicialmente 
por estes profissionais para referirem-se aos casos dessa síndrome que atinge, sobretudo, rapazes reclusos na faixa etária entre 11 e 19 anos, segundo Pinto et al. (1986), que estudaram-na em 10 tribos da região do Alto Xingu. Estas tribos conformam uma sociedade (cf. Dreyfus, 1970) composta por grupos etnolingüísticos dos troncos Aruák, Tupí, Karib e Trumái.

A síndrome, segundo depoimentos de indigenas e de profissionais de saúde, pode provocar sensaçōes de dormência ou "formigamento" progressivo nas extremidades dos membros inferiores e superiores, parestesia, paralisia dos membros, vômitos sanguinolentos, hipertensão seguida de hipotensão, cefaléia e progressiva incapacidade motora, culminando em uma posição fetal e dependência para alimentar-se e locomover-se. Com menor freqüência, ocorre quadro de confusão mental e falência multissistêmica (Bretas Netto et al., 1988) aguda.

A referência mais antiga publicada que se tem da síndrome é a de Nutels (1968), como sendo uma das patologias comuns na região, atribuindo-a a uma "intoxicação pela mucunã (Dolichos pruriens ou D. urens)". Essas espécies de Mucuna foram, porém, confundidas pelo nome com a popular mucunā (Dioclea grandiflora Benth.) tóxica; aquelas são, contudo, o popular "pó-de-mico" (M. Emmerich, comunicação pessoal). A seguir, Gregor (1970; 1977) referiu-se à síndrome, da qual faz uma descrição mais recente em 1985 (Gregor, 1985: 148). Há a descrição de um caso de uma síndrome semelhante, ocorrida com um xamã Kuikúro recluso, em Carneiro (1972), que enfatiza vômitos e dor no abdômen, além da paralisia. Uma "paralisia" ocorrida com um xamã Kamayurá, fora do contexto da reclusão, mas em determinado momento tenso política e socialmente, foi relatada por E. Viveiros de Castro (comunicação pessoal).

Os adolescentes vitimados pela síndrome haviam se submetido ao tradicional rito da reclusão pubertária. Uma vívida descrição da reclusão pubcrtária, incluindo aspectos psicológicos, sociais e sobrenaturais envolvidos, sob o ponto de vista nativo, é feita por Gregor $(1970 ; 1977)$. Durante este rito, os rapazes indigenas devem manter-se sob estrita reclusão no intcrior de suas casas, ingerir misturas feitas com ervas tidas como "fortes" para crescer c tornar-se musculosos, e submeter-se a restrições de 
atividades, alimentares e sexuais. A reclusão masculina acontece em períodos entre 3 e 7 meses, que são interrompidos por intervalos de tempo variados, desde o inicio da puberdade, e que podem ser reiniciados até os quase 20 anos, dependendo das expectativas e da origem familiar.

A reclusão pubertária feminina diferencia-se da masculina, pois as mocinhas são retidas ininterruptamente em um "quarto" dentro de sua residência a partir da primeira menstruação até cerca de um ano depois, quando "a franja cresce até à altura do queixo". As moças submetem-se às mesmas restrições alimentares e de atividades, ingerem ervas consideradas "mais fracas" e têm restrições sexuais que alguns depoimentos apontam como menos estritas que as dos rapazes. Não há casos relatados de doença da reclusão entre as mulheres, à exceção de um único, na aldeia Kuikúro, ainda mal-esclarecido.

Principalmente, durante a reclusão pubertária, os adolescentes encontram-se sob a "proteçāo" e o domínio de uma classe de seres sobrenaturais, os espíritos "donos de remédios" (jiñóto/, em Kuikúro) que podem, segundo acreditam, punir o adolescente que desobedecer as restriçōes (ou mesmo qualquer rapaz," por capricho") fazendo-os "ficar aleijados" (em Kuikúro, /atamikârâ/; em Mehiná$\mathrm{ku}$, makatsiki, "sem pernas"). Esta doença é uma categoria nosológica tradicional do sistema de classificação etnomédico alto-xinguano. A Teoria da Doença xinguana privilegia sintomas localizados nos membros inferiores como forma culturalmente definida desta doença. Ela contém elementos estruturais às representações sobre as doenças $\mathrm{e}$ o corpo, à organização sócio-econômica, política e à cosmologia do Alto Xingu.

A apropriação da síndrome por pesquisadores identificou-a com um quadro de neuropatia periférica, provavelmente de origem exógeno-tóxica. Esta patologia, porém, representa apenas uma faceta da síndrome. De fato, o termo neuropatia periférica, sendo uma categoria nosológica da taxonomia médica ocidental, supervaloriza a dimensão biológica. Contudo, mesmo os profissionais identificados com a abordagem clínico-epidemiológica clássica identificam também "manifestações psicossomáticas", semelhantes à síndrome do pânico e da hiperventilação, ou mesmo outros quadros clínicos que, no contexto 
da reclusão pubertária, são cercados por forte ênfase emocional por parte dos indígenas. No presente artigo, o termo doença da reclusão inclui estas manifestações e as de neuropatia periférica, originando-se em um contexto desencadeador e em uma forma culturalmente determinada de expressão de tensões psicológicas, sociais e políticas. Neste contexto, as rivalidades intra e inter-tribal $e$ as relações com a sociedade nacional envolvente têm um papel fundamental. Por conseguinte, aqui a categoria doença da reclusão designa uma síndrome cultural cujas implicações só o método antropológico é capaz de aprofundar.

\section{A ABORDAGEM CLÍNICO-EPIDEMIOLÓGICA.}

\section{Distribuição de casos de doença da reclusão}

Em uma pesquisa realizada entre 1987-1990, a autora obteve informações acerca de 36 casos de doença da reclusão (Fig. I) entre oito aldeias da área, através de descrição da literatura, levantamento de depoimentos de indígenas e de profissionais de saúde, arquivos médicos locais e de instituições de saúde de fora da área. As limitações da pesquisa e do método qualitativo exigiram a seleção de um dos 10 grupos etnolingüisticos da área para uma estadia mais prolongada, visando aprofundar o assunto. A autora definiu-se pelos Kuikúro, o grupo mais populoso da área, que ocupava posição particular no intrincado quadro das relações interétnicas e na conjuntura política (Figura I).

A maior ocorrência de casos entre os Kuikúro, como se lê no rodapé da Fig. I, deve ser relativizada, pois as características do método motivaram um número maior de depoimentos nesta aldeia. $O$ acesso aos arquivos de instituições de fora da área também limitou-se à totalidade dos casos registrados na população Kuikúro.

Os casos suspeitos, não confirmados como tendo neuropatia, representam tanto a subnotificação quanto as denominadas "manilestações psicossomáticas" da doença da reclusão. Sob o ponto de vista indígena, porém, todas estas manifestacões são casos da categoria tradicional, entre os Kuikúro, de /atamikârâ/. É importante notar que, 
dos 36 casos, 26 foram confirmados como tendo neuropatia periférica, representando esta patologia cerca de $72 \%$ dos casos de doença da reclusão.

\section{FIGURA I}

Casos de Doença de Reclusão (Jatamikârâ/) entre Rapazes do Alto Xingu*, Distribuídos por Triênio de Ocorrência (№ de Casos no Topo das Colunas)

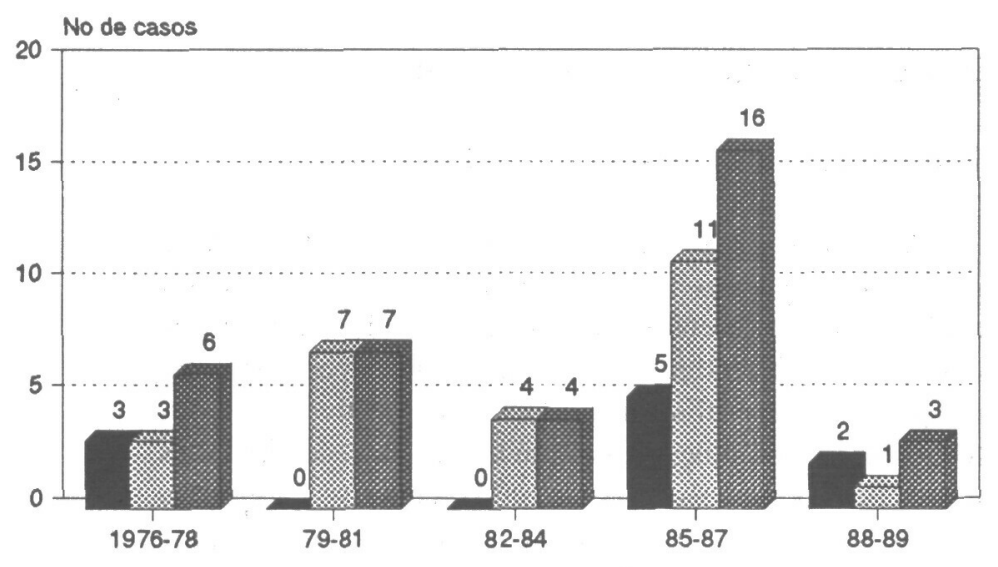

'Kuikúro $=21 ;$ Waurá $=2$; Kamaiurá $=3$; Yawalapiti $=2$; Kalapálo $=3 ;$ Mehináko $=2 ;$ Matipú $=1 ;$ Nahukwá $=2$.

Fonte: Arquivo médico da Funai, da Escola Paulista de Medicina e entrevistas com indigenas e pessoal paramédico entre 1987-1990.

A distribuição da Fig. I cobre um período de 15 anos, mas sabe-se que já surgiu pelo menos 1 caso, em 1991, cujo diagnóstico clínico não confirmou a existência de neuropatia, e sobre os casos anteriores a 1976, o conhecimento é muito vago, como os já citados. 
Os dados subseqüentes restringem-se à aldeia Kuikúro. Embora esta seja a população mais numerosa, a proporção de casos na população estimada em 1985 a partir dos dados de 1990, do grupo de maior risco, aproxima-se de $20 \%$, confirmando uma alta "incidência" neste grupo etnolingüistico naquele ano.

\section{FIGURA II}

\section{Casos da Doença da Reclusão (Jatamikârâ/) entre Rapazes}

Kuikúro, Distribuidos por Ano de Ocorrência, Nivel de Gravidade e Idade (Inscrita em Cada Caso)

\section{Doenca da Rëclusao}

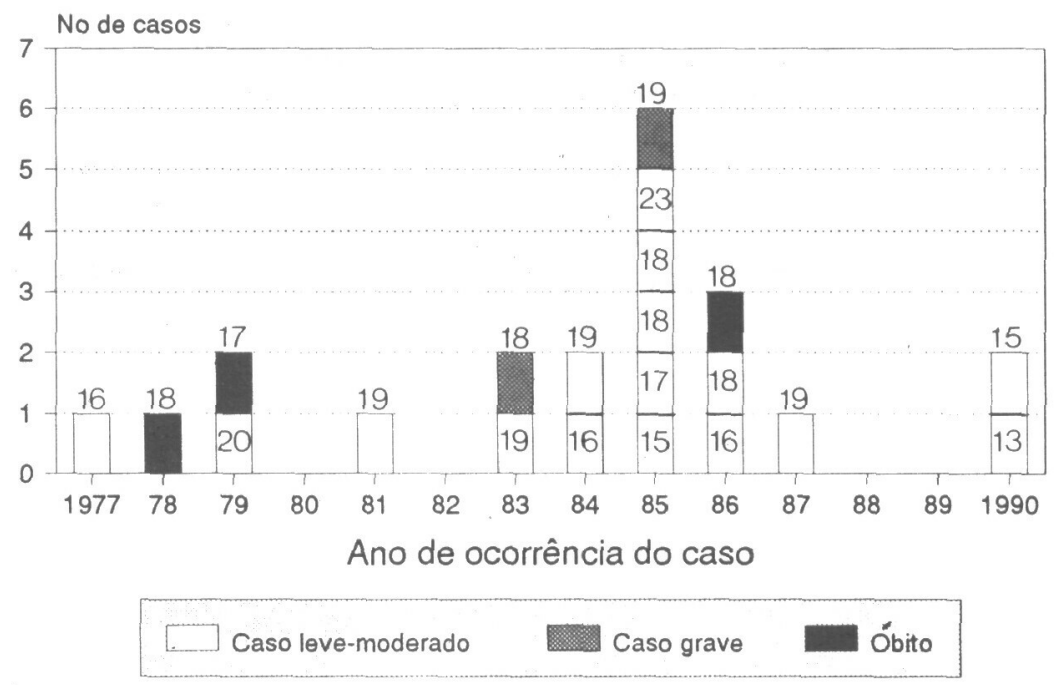

A Figura II evidencia uma concentração de casos entre 1983-86. Destaca-se que entre os 21 casos ocorreram três óbitos, dando uma letalidade de $14,3 \%$. Os óbitos mais os casos graves dão um lote de 5 , que corresponde a $23,8 \%$ - o que indica ser a doença da reclusão um fenômeno de "gravidade patogênica" muito alta. De fato, Pinto et al. (1986) relatam que esta síndrome é responsável por $83 \%$ das causas de morte nesta faixa etária.

A Figura II lembra o perril de um surto epidêmico, mas fala contra doença infecciosa aguda de contaminação em 
fonte única, ou de transmissão interpessoal, porque há intervalos de até 2 anos livres da doença. Houve, portanto, fatores localizados que ensejaram a irrupção de tal surto, os quais devem ser identificados a partir de:

1) Comparação do contexto dos Kuikúro com o contexto dos que tiveram casos esporádicos e os que não tiveram nenhum caso, mas que também passam pelo rito pubertário.

2) Dentro dos Kuikúro, a) alguma particularidade mais evidente no periodo de 1983-1986; b) também algo particular sobre os rapazes entre 17-19 anos (ver Tabela I, que evidencia uma "incidência" particular nesta faixa etária).

\section{TABELA I}

Taxas de Incidência por Idade da Doença da Reclusão entre Rapazes Kuikúro do Alto Xingu entre 1977-1990

\begin{tabular}{cccc}
\hline \hline $\begin{array}{c}\text { Idade } \\
\text { em anos }\end{array}$ & $\begin{array}{c}\text { Rapazes com } \\
\text { a idade N }\end{array}$ & $\begin{array}{c}\text { Casos } \\
\mathrm{n}\end{array}$ & $\begin{array}{c}\text { Taxas de } \\
\text { incidencia }\end{array}$ \\
\hline 13 & 39 & 1 & 2,6 \\
14 & 37 & 0 & - \\
15 & 38 & 2 & 5,3 \\
16 & 36 & 3 & 8,3 \\
17 & 39 & 2 & 5,1 \\
18 & 41 & 6 & 14,6 \\
19 & 38 & 5 & 13,2 \\
20 & 38 & 1 & 2,6 \\
$\ldots$ & $\ldots$ & $\ldots$ & $\ldots$ \\
23 & - & 1 & - \\
\hline \hline
\end{tabular}

No que se refere à idade em que a doença da reclusão atinge mais intensamente os Kuikúro, os resultados da Tabela I mostram que é na laixa de 15-19 anos, com evidente pico de ataque na idade de 18-19 anos. Tal 
distribuição é compatível com fatores patogênicos do âmbito do "rito da puberdade", porém não se limita a isso porque o pico aos 18 anos indica enorme atraso do advento dos efeitos psicopatogênicos do rito. A concentração de casos depois dos 15 anos, com pico de ataque aos 18-19 anos, sugere que a doença em pauta avoluma-se no ingresso na maioridade.

Outra observação a destacar é a grande variação da puberdade, que na área cultural em questão começa aos 11 anos de idade, embora nos reclusos antes dos 13 anos não se tenha registro de casos. Se isso é verdade, a elevação etária da submissão ao rito poderia indicar que, nesta aldeia, essa prática da tradição indígena está perdendo sua finalidade originária.

\section{TABELA II}

Casos de Doença da Reclusão entre os Rapazes Kuikúro Segundo o Local em que Receberam Tratamento/Assistência e Segundo a Evolução dos Casos

\begin{tabular}{lccccc}
\hline \hline Local de atendimento & & Óbito & Grave & Leve-moderado \\
\hline & $\mathrm{n}$ & $\%$ & $\mathrm{n}$ & $\mathrm{n}$ & $\mathrm{n}$ \\
Aldeia & 9 & 42,9 & 3 & - & 6 \\
São Paulo & 7 & 33,3 & - & 1 & 6 \\
Brasilia & 5 & 23,8 & - & 1 & 4 \\
\hline Total & 21 & 100,0 & 3 & 2 & 16 \\
\hline \hline
\end{tabular}

A classificação dos casos em graves, moderados e leves considera os critérios dos indígenas, que enfatizam a dificuldade em alimentar-se como um dos sinais críticos, além da conjuntura sócio-política. A importância desta classificação nativa reflete-se no direcionamento das opçōes terapêuticas, orientando a preferência pelo tratamento médico ocidental fora da área nos casos graves $\mathrm{e}$ moderados. A tabela II mostra que aproximadamente $43 \%$ dos casos ficam na própria aldeia. Os óbitos, todos ocorridos na área, foram um dos fatores que determinaram a opção para recorrer a tratamento fora da aldeia. Isso permite levantar a hipótese de que há um maior número de 
casos de /atamikârâ/, de gravidade leve-moderada, em especial os "psicossomáticos", que ficam desconhecidos dos serviços médicos.

Esses dados levantam a questão da Saúde dos Índios. Sejam quais forem as causas da referida doença, um bom serviço assistencial próximo às aldeias evitaria os óbitos, cuidando ali mesmo dos doentes. Num contexto como esse, é sumamente difícil falar em prevenção de ocorrência, porque isso requer intervenção em um ritual de um povo.

\section{Hipóteses etiológicas da neuropatia periférica}

Esta patologia é descrita por Pinto et al. (1986) e Gabbai et al. (1986) como uma neuropatia, apresentando atrofia distal e fraqueza nos membros, com reflexos dos tendões diminuídos ou inexistentes e hipostesia distal, e com comprometimento dos nervos periféricos identificado por biópsia. Bretas Netto et al. (1988) descrevem um caso como uma poliradiculoneurite e falência multissistêmica, com um quadro semelhante à síndrome de Guillain-Barré.

Claramente, os profissionais de saúde e pesquisadores imputam como etiologia provável a ingestão de ervas durante a reclusão pubertária (cf. Nutels, 1968; Gabbai et al., 1986; Pinto et al., 1986; Bretas Netto et al., 1988). Tradicionalmente, elas são utilizadas como "remédios" (escolhidos de um repertório de no mínimo 12 categorias nativas de "eméticos" e outras tantas de "ungüentos"). Para os indigenas, porém, estes remédios são uma etiologia, no máximo, de um nível instrumental, pois é o espírito "dono dos remédios" ou um feiticeiro a causa agencial. O contexto da quebra das regras alimentares e sexuais é enfatizado como causalidade última (cf. Zempléni, 1985, sobre os níveis de causalidade). Para a epidemiologia, contudo, ainda não há dados suficientes para comprovar aquela hipólese. Na sua maioria, as plantas não estão identilicadas botanicamente, nem as suas qualidades patogênicas analisadas farmacologicamente. Somente uma espécic, a Dioclea erecta Hochne, dentre as cinco espécies identilicadas até o momento (cf. Emmerich et al.,1990), justifica a hipótese de toxicidade, pois pertence à mesma familia de uma outra espécic comprovadamente tóxica, a 
Dioclea grandiflora Benth., vulgarmente conhecida como mucunã (cf. Chaves et al., 1948). Contudo, nenhum dos rapazes vitimados que foram entrevistados relata tê-la ingerido. Além disso, a seiva de cada uma destas espécies de "eméticos" é ingerida misturada a grandes quantidades de água, expelida em vômitos provocados.

Segundo Bretas Netto et al. (1988), foi constatado no exame de sangue de um paciente a presença de organofosforados e da droga psicodisléptica "banisterina", substância com radical "indol". A imputação de uma etiologia tóxica a uma espécie vegetal especifica em Bretas Netto et al. (1988) pode ser considerada uma inferência apressada, pois tal espécie não é utilizada nos rituais daquela área cultural, ao menos no que concerne às pesquisas etnobotânicas realizadas até agora. Se a presença de elementos alucinogênicos fosse confirmada na área, isto seria um dado etnográfico original e surpreendente. Quanto à presença de organofosforados na amostra sangüínea do paciente, aspectos epidemiológicos, bioquímicos e etnobotânicos deveriam ser considerados em uma pesquisa mais acurada. Embora o inseticida Audrin realmente tenha sido usado na área durante um certo período,"para matar formigas", a presença de organofosforados no sangue do rapaz não poderia ser significativamente associada aos demais casos de neuropatia devido aos seguintes fatores:

a) tal inseticida é utilizado nas roças por adultos, sendo o adolescente recluso impedido de realizar trabalho agricola;

b) a manipulação de alimentos para o recluso é feita exclusivamente por uma mulher entre as mais velhas de sua familia, consistindo basicamente de beiju e de uma bebida feita de farinha de mandioca brava ralada, seca e cozida. Ela, contudo, manipula alimentos para toda a família;

c) se os casos de neuropatia estivessem associados ao uso do inseticida e à contaminação dos alimentos, por que somente os reclusos, que estão cercados por restrições de várias ordens, adoecem? Este mesmo argumento contrapõe-se à hipótese de contaminação ambiental por organofosforados (Gabbai et al., 1986).

Dentre as etiologias tóxicas, a alimentar foi descartada por critérios epidemiológicos: o grupo de adolescentes do 
sexo feminino funciona como um grupo controle natural e as restriçōes alimentares são as mesmas, tanto para os homens quanto para as mulheres, sendo estas últimas submetidas durante períodos mais longos. $O$ sumo de mandioca brava longamente cozido, que faz parte da dieta regular daquela população (cf. Osuntokum, 1973, sobre a neuropatia tóxica africana), não é ingerido pelos reclusos por inserir-se na categoria de alimentos doces, proibidos. A etiologia nutricional por carência não se coaduna com o quadro agudo da síndrome (Baruzzi e Pinto , comunicação pessoal), além deste não atingir as moças reclusas.

Finalmente, a categoria neuropatia periférica admite outras etiologias que não a exógena tóxica, em que destaco a endógena.

Trata-se, portanto, de uma patologia que, ao menos nos seus aspectos etiológicos, não está conclusivamente descrita.

\section{IMPLICAÇÕES CULTURAIS DA DOENÇA DA RECLUSÃO}

\section{O sentido cultural de /atamikârâ/}

A reclusão pubertária faz parte de um complexo de reclusões importante na cultura alto-xinguana que demarca estados liminares entre os estados sociais. A couvade e a reclusão de iniciação ao xamanismo são outros destes estados. Parte deste complexo são os momentos liminares que acompanham a menstruação feminina, os periodos antes de lutas inter-tribais e de doenças graves. Estados e momentos cercados por regras restritivas de atividades, alimentares e sexuais, eles exprimem a crença na construção social do corpo e da pessoa, assim como reafirmam a necessidade de um ascetismo fundamental ao ethos alto-xinguano. É este ethos que mantém o tecido da sociedade alto-xinguana coeso. A reclusão pubertária é certamente aquela que apresenta uma conotação mais forte neste sentido.

Para os indígenas, o contexto da reclusão pubertária reúne expectativas familiares e sociais na capacidade de autocontrole do adolescente recluso; restriçōes de atividades sexuais e alimentares consideradas dificeis de serem 
cumpridas, porém cruciais para a formação das qualidades físicas e morais do adulto e da pessoa alto-xinguana (cf. Viveiros de Castro, 1977; 1978 e 1979); e a presença ameaçadora e incontrolável do sobrenatural, propiciando punição para a quebra destas regras restritivas.

Para os alto-xinguanos, /atamikârâ/ é um dos riscos calculados da reclusão pubertária. Significa uma punição sobrenatural do espírito/iñóto/ para o comportamento indisciplinado do adolescente que desrespeitou as regras restritivas. Esta etiologia, contudo, é enfatizada por indivíduos não vinculados ao grupo de substância da vítima. Existem alternativas etiológicas que a cultura admite: a imprevisibilidade deste espírito, que pune "à toa", ou acontecimentos incontroláveis, como a poluição pelo sangue feminino, menstrual ou do parto. Para os membros do grupo de substância das vítimas, porém, a etiologia mais conclusiva é a feitiçaria. Sendo esta última uma etiologia eminentemente social, expressa a predominância de um contexto adverso. Estas etiologias constituem alternativas ao estigma deletério da identidade do grupo que /atamikârâ/ representa, revertendo a posição do grupo de acusados para vítimas.

Uma das alternativas conhecidas para os indivíduos que não conseguem "alcançar sucesso ou obter satisfação dentro de um campo de possibilidades histórica e socialmente delimitado é o afastamento, o rompimento com um mundo que se torna opressivo e indesejável" (Velho, 1987: 46). Talvez isto explique a maior "incidência" da doença na faixa etária entre 18-19 anos. É no ingresso na maioridade que os adolescentes já deveriam ter provas de suas possibilidades como campeões, que thes propiciaria aspirar posição de prestígio. Quando os adolescentes falham, as exigências sociais e culturais podem tornar-se insustentáveis.

O contexto da reclusão pubertária fornece elementos suficientes para considerarmos o adolescente como submetido a uma situação de estresse em que as expectativas pessoais, familiares e de toda a comunidade da aldeia se voltam para ele. Os fatores de "estresse" não devem ser considerados sob o ponto de vista individualista, que aponta para "estressores" específicos associados a patologias específicas. Cassel (1974) critica esta abordagem, um 
reducionismo permeado pela ideologia individualista (cf. Young, 1980). Considero estes fatores como uma conjuntura, um contexto social e cultural que reúne diversos aspectos que conformam uma situação de estresse que propicia as doenças em geral. A existência de casos de doença da reclusão não confirmados como neuropatia periférica, embora apresentando um quadro sintomatológico semelhante aos de casos confirmados, são evidências da atualidade do fenômeno da eficácia simbólica.

Seguindo a tradição de Lévi-Strauss (1977), que inspirou-se em Cannon (1942) para enfrentar o problema da eficácia simbólica, a antropologia tem buscado estabelecer relações entre os níveis simbólicos da cultura e os processos endógenos de adoecimento e cura (cf. Moerman, 1979 e 1983 ; Bibeau, 1983). Neste sentido, os estudos em endocrinologia e o papel das endorfinas nestes processos têm fornecido um importante elo de ligação entre os aspectos simbólicos da cultura e os fenômenos biológicos (cf. Prince, 1976 e 1982a e b). No entanto, mesmo que a base fisiológica da ligação entre os aspectos simbólicos e os biológicos não esteja estabelecida, o sentido cultural dos processos saúde-doença devem ser explicitados.

Cabe, neste momento, perguntar se mesmo naquelas manifestações em que os procedimentos biológicos de medicina clínica encontraram uma lesão orgânica, não estariam também implicados fatores de ordem simbólica no processo saúde-doença.

Esta questão é levantada pelo comportamento apresentado na figura II durante o triênio 1984-86. O comportamento "epidêmico" da doença neste período permite-nos indagar se essa síndrome não seria também bastante suscetivel aos fatores pessoais, sociais e políticos.

No caso da doença da reclusão, que fatores entre os domínios do cultural (incluindo conjunturas sócio-políticas, a organização econômica e a cosmologia) poderiam estar relacionados com o domínio dos fenômenos biológicos?

Estes fatores são dífíceis de serem identificados em cada situação particular no ano de 1985, pois o método da observação participante teria sido necessário. Por outro lado, os anos de 1988 e 1989 também apresentam características atípicas no comportamento anual dos casos entre os Kuikúro. 
Por que, se o contexto do ritual, a dieta, o repertório de plantas medicinais e o número de reclusos não se alteraram significativamente, o número de casos ocorridos entre os Kuikúro no triênio 88-90 é tão baixo, chegando mesmo a zero em 88-89, após um período epidemiológico tão significativo como o triênio 85-87 (cf. fig. II) ? A subnotificação não parece ser o caso, pois foi exatamente neste período que a pesquisadora permaneceu na aldeia por longos periodos, atenta a qualquer possibilidade. Não havia nenhum impedimento de ordem cultural que dificultasse o acesso aos casos. A alegada dificuldade em obter dados, devido a fatores culturais (Pinto et al. 1986), revela a inadequação do método epidemiológico nesta situação e a necessidade de uma equipe multidisciplinar que inclua profissionais com treinamento antropológico.

Dentre os fatores culturais que têm relação direta com a conjuntura sócio-política e das relaçōes de contato, um fato é predominante. Durante o inicio de 1988, a produção de filmagem da obra cinematográfica "Kuarup", na área do Posto Leonardo, mobilizou uma equipe de cerca de 150 pessoas que viveram na área, reproduzindo uma estrutura de serviços semelhantes às encontradas em áreas urbanas. Para aquela área indígena, a grande quantidade de pessoas acampadas com seus pertences, os serviços de restaurante, sala de jogos, televisão, lavanderia, banheiros e posto de venda de cigarros, a disponibilidade de barcos, gasolina e vôos semanais para fora do parque, tudo isto significou um contato intenso com o estilo de vida urbano. Principalmente, aquela "cidade de brancos" constituiu um mercado para venda de artesanato, fonte de renda assalariada, assim como possibilitou um fluxo regular para a aquisição de inúmeros objetos industrializados. Finalmente, os meios de transporte disponíveis intensificaram o trânsito aéreo, fluvial e rodoviário para a região, ligando o Posto Leonardo a médios e grandes centros urbanos.

O evento representou uma válvula de escape para as tensōes advindas das rivalidades intra e inter-tribais, direcionando as expectativas para o contato e o comércio com a sociedade envolvente e permitindo aos alto-xinguanos acesso direto à civilização por terra. $O$ acesso por via terrestre a uma cidade próxima aos limites sul do Parque os tornaram independentes dos constrangimentos de 
buscar saída pelos limites norte, território habitado por grupos étnicos rivais. Para os Kuikúro especialmente, a via de acesso ao sul do Rio Kuluene, território tradicionalmente de domínio dos grupos Karíb, significou independência dos Yawalapiti, seus tradicionais oponentes na disputa pela hegemonia das relações de contato, pois deixaram de depender da disposição destes últimos, que detêm postos-chave na administração dos recursos do Posto Leonardo, em facilitar-lhes os meios.

Principalmente, significou a independência dos problemas de saúde e, em particular, dos casos de doença da reclusão, que, devido à sua gravidade ser reconhecida pelos profissionais de saúde, consistiam garantia de vaga em um dos voôs da Funai (Fundação Nacional do Índio). A tentativa de usar os problemas de saúde como meio de possibilitar acesso aos centros urbanos e obter objetos industrializados necessários às atividades econômicas (como anzóis e linhas de pesca, machados e linhas de algodão) e bens de prestígio é bastante reconhecida pelos profissionais de saúde. Após o desmantelamento da estrutura da produção da filmagem e o esgotamento dos recursos financeiros e operacionais adquiridos por este meio, os Kuikúro voltaram a ter necessidade de estabelecer novas relações e meios de contato com a sociedade nacional, estreitando os laços com as fazendas vizinhas e as cidades próximas ao limite sul do parque.

O uso sócio-político dos problemas de saúde expressam a noção presente nesta sociedade indígena de que a doença não é meramente um acontecimento de ordem biológica, mas igualmente um acontecimento que expressa uma conjuntura adversa em termos pessoais, sociais e políticos. Desta maneira, a imputação dos casos de /atamikârâ/ à feitiçaria é o testemunho da importância destas ordens de fenômenos na concepção indígena sobre a doença.

A síndrome significa um meio de expressão da insatisfação dos adolescentes com as obrigações penosas e perigosas do ritual da reclusão pubertária e com a carreira tradicional de lutador, base do prestígio social e político nesta sociedade.

As "carreiras de branco", como líder faccional mediador das relações de contato (o "chefe de branco"), funcionário da Funai (barqueiro, operador de rádio e funcionário 
administrativo, entre outros) e agente de saúde ou de educação, passaram a constituir, para os adolescentes, alternativas à carreira de lutador.

Isto significa que, ao contrário de grupos de contato recente em que as identidades de índio e branco são vistas como paradoxais (cf. Da Matta, 1976: 421), os alto-xinguanos passaram a incorporar a sociedade ocidental, incluindo seus agentes, artefatos e seu sistema de medicina, como logicamente compatível com sua visão de mundo. Na cosmologia alto-xinguana, as identidades de "branco" e "índio" passaram a ser incorporadas como identidades complementares, sendo o universo ocidental englobante em um outro nível, como o é o mundo sobrenatural (sobre a lógica hierárquica e o englobamento dos opostos; cf. Dumont, 1985).

O tratamento dos casos de doença da reclusão em centros urbanos distantes das aldeias passou a ser interpretado, segundo a lógica própria à cosmologia alto-xinguana que associa os "brancos" ao sobrenatural, como uma socialização altemativa, isto é, uma outra, e mais radical, reclusão que inicia os adolescentes no universo ocidental.

$O$ fato de que existe uma manifestação de uma patologia cujos exames clínicos identificam uma lesão biológica significa simplesmente que esta patologia serviu como um significante ao qual os indígenas atribuem um significado social e cultural. Aqueles casos não confirmados como neuropatia periférica, as denominadas "manifestações psicossomáticas" de doença da reclusão, não são meras simulações. São a forma culturalmente informada de expressão corporalizada de conjunturas pessoais, sociais, políticas e cosmológicas adversas.

As implicações culturais da doença da reclusão para a epidemiologia

O termo doença da reclusão designa uma categoria da situação de contato intercultural, utilizada pelos profissionais de saúde, que inclui uma categoria da medicina tradicional e uma outra da medicina ocidental moderna, definida a partir de métodos biológicos, como a biópsia dos nervos (Gabbai et al., 1986). A categoria biomédica reflete procedimentos classificatórios e métodos desenvol- 
vidos pela medicina clínica a partir de uma mudança estrutural na visão de mundo moderna (cf. Foucault, 1980), fruto de um processo histórico-cultural.

Dentre estes procedimentos, gostaria de destacar alguns fenômenos, como o reducionismo do contexto pessoal, sintetizado na noção ontológica de doença, que impediria com que associações causais extra-biológicas, como as psicológicas, sociais, político-econômicas e culturais, fossem percebidas como intervenientes em níveis distintos de determinação das doenças.

Cardim et al. (1991) consideram que a dificuldade da epidemiologia em encontrar associações de caráter extra-biológico dos fenômenos de doença é uma questão da inadequação do método para detectar estas associações.

No âmbito da epidemiologia social, a questão da multicausalidade das doenças tem sido abordada sob uma perspectiva quantitativo-coletiva.

Esta questão deveria ser pensada no âmbito das implicações do Individualismo, fundamental na visão de mundo ocidental moderna, que tem no Indivíduo enquanto Valor, um ser moral (não confundir com o indivíduo empírico), a noção de Pessoa (cf. Dumont, 1985; Duarte, 1986; Velho, 1987). Uma das características do Individualismo é a fragmentação da realidade com a conseqüente especialização do conhecimento em disciplinas com idêntico estatuto epistemológico (sobre a noção de "planos homólogos", cf. Dumont, 1985: 272-275). São efeitos da visão de mundo moderna o "desencantamento do mundo" e o "achatamento" da realidade (cf. Duarte, 1986), os quais a noção ontológica de doença e o dilema da multicausalidade atualizam.

Possas (1989: 188), citando Laurell, lembra haver uma "caixa preta" entre o nivel biológico e o nível macro das determinações sociais, indicando falta de articulaçāo teórica entre estes dois níveis. No mesmo sentido, Goldberg (1990) insiste que, a nível individual, identificam-se microvariáveis, mas a epidemiologia remete o dano à população, e aqui imperam as macrovariáveis, que é o continente das micro. Possas (1989) enfatiza que as várias instâncias de determinações do processo saúde-doença deveriam ser examinadas a partir da noção de hierarquia causal, identificando o referido efeito de "achatamento do 
real". Pode-se concluir, portanto, que existe um movimento de busca da integralidade dos fenômenos da saúde-doença. $\mathrm{Na}$ visão de mundo ocidental moderna, a busca da inteireza dos fenômenos apresenta-se sob a noção de integridade, e não de totalidade (Dumont, 1985: 261). A visão de mundo tradicional, porém, é holista.

Neste nível da análise, também a questão da relação indivíduo-sociedade precisa ser examinada sob uma perspectiva qualitativa, no contexto da articulação entre o cultural e o biológico, enfrentando-se a dicotomia cartesiana corpo $x$ mente e o papel dos mecanismos endógenos de adoecimento e auto-cura.

$O$ uso da categoria doença da reclusão reflete a percepção dos profissionais de saúde, no contexto intercultutal, dos limites das categorias biomédicas e da especialização científica, apontando para a necessidade da interdisciplinaridade. Contudo, se a perspectiva interdisciplinar for levada às últimas conseqüências pela epidemiologia, neste caso, deveriamos entrar no campo da antropologia médica (ou da antropologia da doença, tais matizes distintivos não vêm ao caso, no momento). Neste campo, a conclusão seria que a doença da reclusão é uma síndrome cultural, um fenômeno com implicações de várias ordens, inclusive a biológica, que a cultura alto-xinguana define muito mais adequadamente pelos termos que a designam nas línguas locais. O termo doença da reclusão só tem sentido aqui como uma tradução, e para chamar a atenção para problemas de ordem metodológica e teórica da epidemiologia diante dos fatores culturais associados ao processo saúde-doença. Por outro lado, para melhor dar conta da doença enquanto objeto de estudo, a antropologia também deve levar em conta o método epidemiológico e considerar estes problemas.

This article presents an anthropological approach to the symbolic aspects of the disease, considering traditional representations about the puberty seclusion syndrome which affects adolescent indians from the Upper Xingu 
region (Central Brazil), in a comparative perspective with the clinical-epidemiological approach. The traditional nosological category and its etiological implications in indigenous medicine and culture are contrasted with the western medical category - $a$ peripheral neuropathy, possibly of toxic origin identified in some cases of the syndrome. An epidemiological analysis of the data collected from the traditional point of view shows relations with events of cultural origin, associated with social and political contexts and with the nature of cross-cultural relations. Moreover, this culture-bound syndrome presents some methological issues for western medicine, particularly for biomedical and social-epidemiological approaches. Finally, the authors make explicit some cultural assumptions characteristic of modern western society, underlying the procedures used by the scientific disciplines involved.

\section{REFERÊNCIAS BIBLIOGRÁFICAS}

BARUZZI, R. G. \& PINTO, N. R. S. - Male puberty seclusion and risk of death in Indians from Alto Xingu, Central Brazil. American Journal of Physical Anthropology, 81: 191, 1990.

BASSO, E. - The Kalapalo Indians of Central Brazil. New York, Holt, Rinehart \& Winston, 1973.

A Musical View of the Universe: Kalapalo Myth and Ritual Performances. Philadelphia, University of Pennsylvania Press, 1985.

BIBEAU, G. - L'Activation des mecanismes endogènes d'autoguérison dans les traitements rituels des Angbandi. Culture 3: 33-49, 1983.

BRETAS NETTO, C.; LUCAS, W.; CARVALHO, C. M.; SIMÕES, E. P. \& VISCARDI, R. C. - Intoxicação exógena por indol em indígena - relato de um caso. IV Congresso Brasileiro de Medicina Intensiva, Resumos, p. 83, Brasília, 1988.

CANNON, W. B. - The emergency function of the adrenal medulla in pain and the mayor emotions, American Journal of Physiology, 33: 356-372, 1914. 
Stresses and strains of homeostasis. American Journal of Medical Sciences, 189: 1-14, 1935.

Voodoo death. American Anthropologist, 44: 169-181, 1942.

CARDIM, M. S. ; AZEVEDO, B. A. \& MORGADO, A. F. - O que a Epidemiologia pode ainda fazer de relevante. Cadernos de Saúde Pública, 7: 6-16, 1991.

CARNEIRO, R. - Recent observations on shamanism and witchcraft among the Kuikuru Indians of Central Brazil. Annals of the New York Academy of Sciences, 293: 215-228, 1972.

CASSEL, J. - Psychosocial Processes and "Stress": Theoretical Formulation. International Journal of Health Services, 4: 471-482, 1974.

CHAVES, N.; TEODOSIO, N. R.; LIMA, O. G. \& PESSOA, W. A "mucunã" (Dioclea grandiflora Benth.) na Nutrição. Recife, Laboratório de Fisiologia da Faculdade de Medicina da Universidade do Recife, 1948.

DA MATTA, R. - Quanto custa ser índio no Brasil? Considerações sobre o problema da identidade étnica. Revista Dados, 13: 33-54, 1976.

Ensaios de Antropologia Estrutural, (org.), Petrópolis, Ed. Vozes, 1973.

DOLE, G. - Shamanism and Political Control among the Kuikuru. In: Beitrage zur VolkerKunde Südamerikas (volkerkundliche Abhandlungen), B.I., Hanover, pp. 53-62, 1964.

Anarchy without chaos: Alternatives to political authority among the Kuikuru. In: Political Anthropology. (M. Swarz, A. Tuden \& V. Turner (ed)), pp. 73-87, Chicago, Aldine Publications, 1966.

DOW, J. - Universal aspects of symbolic healing: a theoretical synthesis. American Anthropologist, 88: 56-69, 1986.

DREYFUS, S. - Alliances inter-tribales et systèmes de parenté du Haut Xingu ( Brésil Central). In: Echanges et Communications: Mélanges Offertes d Claude Lévi-Strauss. (J. Pouillon \& P. Maranda (eds)), pp. 258-271, Haia, Mouton, 1970.

DUARTE, L. F. D. - Da Vida Nervosa nas Classes Trabalhadoras Urbanas. Rio de Janeiro, Jorge Zahar Editora, 1986.

DUMONT, L.- $O$ individualismo: Uma perspectiva antropológica da ideologia moderna. Rio de Janeiro, Rocco, 1985.

DYCK, P. J. - Manifestações de polineuropatia periférica. In: Tratado de medicina interna. (Cecil-Loeb; Beeson \& Mc Dermont (orgs.)), pp. 1006-1010, Rio de Janeiro, Ed. Panamericana Ltda., 1977. 
EMMERICH, M. \& SENNA, L. M. - Estudos de etnobotânica no Parque Indígena do Xingu - 1. Uma periandra (Leguminosae) nova. Boletim do Museu Nacional (Botânica), n.s., 57: $1-3,1980$.

Estudos de etnobotânica no Parque Indigena do Xingu. 6. Fortificantes. BRADEA, Boletim do Herbarium Bradeanum, 5(37), 1990.

FOUCAULT, M. - O Nascimento da Clínica. Rio de Janeiro, Forense-Universitária, 1980.

GABBAI, A. A.; SCHIMIDT, S.; OLIVEIRA, A. S. B. \& PINTO, N. R. S. - An original peripheral neuropathy associated with a seclusion rite in male adolescent brazilian indians. Muode \& Nerve, 9 (suppl): 123, 1986.

GOLDBERG, M. - Este obscuro objeto da epidemiologia. In: Epidemiologia - Teoria e Método. Costa, D. (org), pp. 87136, São Paulo, Hucitec, 1990.

GREGOR, T. - Exposure and seclusion: a study of institutionalized isolation among the Mehinacu indians of Brazil. Ethnology, 9: 234-250, 1970.

Mehinaku: The Drama of Daily Life in a Brazilian Indian Village. Chicago, The University of Chicago Press, 1977.

Anxious Pleasures: the sexual lives of an amazonian people. Chicago, The University of Chicago Press, 1985.

LÉVI-STRAUSS, C. - Antropologia Estrutural I. Rio de Janeiro, Tempo Brasileiro, 1977.

MOERMAN, D. E. - Anthropology of symbolic healing. Current Anthropology, 20: 59-90, 1979.

Physiology and symbols: The anthropological implications of the placebo effect. In: The anthropology of medicine, from culture to method. (Romanucci Ross, L.;

Moerman, D. E. \& Tancredi, L. R.), pp. 156-167, Manchester, Bergin and Gatvey Publishers, 1983.

NUTELS, N. - Medical problems of newly contacted indians. In: Biomedical challenges presented by the american indian. Washington, Pan American Health Organization, Publication n. $165: 68-76,1968$.

OSUNTOKUN, B. O. - Ataxic neuropathy associated with high cassava diets in West Africa. In: Chronic cassava toxicity: an interdisciplinary worshop. London, International Development Research Centre Monographs, pp. 127-138, 1973.

PINTO, N. R. S. \& BARUZZI, R. G. - Neuropatia periférica aguda associada à reclusão pubertária masculina em indios do Alto Xingu, Brasil Central. Revista da Sociedade Brasileira de Medicina Tropical, 19 (supl.): 118, 1986.

POSSAS, C. - Epidemiologia e Sociedade: Heterogeneidade Estrutural e Saúde no Brasil. São Paulo, Hucitec, 1989. 
PRINCE, R.- Psychotherapy as the manipulation of endogenous healing mechanisms: a transcultural survey. Transcultural Psychiatric Research Review, 13: 115-133, 1976.

The endorphins: a review for psycholgical anthropologists. Ethos, 10: 299-302, 1982a.

Shamans and endorphins: hypothesis for a synthesis. Ethos, 10: 409-423, $1982 \mathrm{~b}$.

VAN GENNEP, A. - Os ritos de passagem. Petrópolis, Vozes, 1978.

VELHO, G. - Individualismo e cultura: notas para uma antropologia da sociedade contemporanea. Zahar, Rio de Janeiro, 1987.

VIVEIROS DE CASTRO, E. B. - Individuo e sociedade no alto Xingu: Os Yawalaptti. Dissertação de Mestrado. Programa de Pós-Graduação em Antropologia Social, Museu Nacional (inédito), 1977.

Alguns aspectos do pensamento Yawalapiti: classificação e transformaçōes. Boletim do Museu Nacional (Antropologia), n.s., 1978.

A fabricação do corpo na sociedade xinguana. Boletim do Museu Nacional (Antropologia), n.s., 32: 40-49, 1979.

YOUNG, A. - The discourse on stress and the reproduction of conventional knowledge. Social Science \& Medicine, 14B: 133-46, 1980.

ZEMPLÉNI, A. - La maladie et ses causes. L'Ethnographie, 96/97: 13-44, 1985. 